Corrigendum

\title{
Corrigendum to "Characterization of the CYP2D6 drug metabolizing phenotypes of the Chilean mestizo population through polymorphism analyses" [Pharm. Res. 101 (November) (2015) 124-129]
}

\author{
Nelson Varela ${ }^{a, b}$, Luis A. Quiñones ${ }^{a, *}$, Jana Stojanova ${ }^{a}$, Joselyn Garay ${ }^{a}$, Dante Cáceres ${ }^{a, c}$, \\ Silvia Cespedes ${ }^{a}$, Jaime Sasso ${ }^{a}$, Carla Miranda ${ }^{a}$ \\ a Laboratory of Chemical Carcinogenesis and Pharmacogenetics, ICBM, Program of Molecular and Clinical Pharmacology, Faculty of Medicine, University of \\ Chile, Chile \\ ${ }^{\mathrm{b}}$ Department of Medical Technology, Faculty of Medicine, University of Chile, Chile \\ ${ }^{\mathrm{c}}$ Environmental Health Program, School of Public Health, Faculty of Medicine, University of Chile, Chile
}

Since the publication of this article [1] the authors have noticed that in Fig. 1D, the genotype * $2 /{ }^{*} 2 \times N$ was not identified in the adjacent lane to the standard (Std) line. In addition, in the Introduction the statement "We studied the presence of CYP2D6*2 (2850C >T, rs1135840, R296C)" should be read as "We studied the presence of CYP2D6*2 (2850C>T, rs16947, R296C)". "rs1135840" in Table 2 should have been "rs16947". The statistical analyses of Table 3 were done using the chi squared test and not the one-way ANOVA and Student's test.

The authors apologise for any inconvenience these mistakes may have caused.

\section{Reference}

[1] N. Varela, L.A. Quiñones, J. Stojanova, J. Garay, D. Cáceres, S. Cespedes, J. Sasso, C. Miranda, Characterization of the CYP2D6 drug metabolizing phenotypes of the Chilean mestizo population through polymorphism analyses, Pharmacol. Res. 101 (November) (2015) 124-129, http://dx.doi.org/10.1016/j.phrs.2015.07.020. 